\title{
ASTRONOMICAL HOSTING IN CENTRAL ASIA
}

\author{
A. Pozanenko ${ }^{1}$, A. Volnova ${ }^{1,2}$, S. Guziy ${ }^{3}$, N. Tungalag ${ }^{4}$, E. Klunko ${ }^{5}$ \\ and I. Molotov ${ }^{6}$
}

\begin{abstract}
Networked projects e.g. Gamma-Ray Burst follow up optical observations require dense worldwide coverage. We are investigating potentially interesting sites for observatories in Central Asia where coverage by observatories is still poor. One of the most important parameter of a site is a number of clear night hours. We present first results of direct parameter measurements gathered with weather stations and our own observations in different sites of Mongolia.
\end{abstract}

\section{Data analysis and results}

Site selection. Our project was started from a selection of sites for investigation in Mongolia. The basic approach in the first step is to locate the sites with maximal number of clear sky night hours and minimal annual ground wind speed. We were inspired by early reports by Batsukh et al. (1995) about number of astronomical observational hours. To start our investigation we referred on the Atlas of the climate and ground water resources in the Mongolia (1985). The southern region of Mongolia has a maximal number of sunshine days, and at the same time west part of the region is high-mountain desert within spurs of Mongolian-Altai. This type of relief can be suitable for good quality of astronomical observations. We obtained data from several weather stations in the provinces (aimak) of Umnugovi, Govi-Altay, Bayanhongor. Usually weather stations are placed in the central settlement of area (sum). Additionally we use the data of our own monitoring in the site of Tavantalgoi (50 km west from Ulaanbaatar) and Sayan Solar Observatory (SSO) nearby Mondy settlement, Russia (Fig. 1 and Table 1).

\footnotetext{
1 Space Research Institute, RAS, Moscow, Russia; e-mail: apozanen@iki.rssi.ru

2 Sternberg Astronomical Institute of Lomonosov Moscow State University, Moscow, Russia

3 Mykolaiv National University, Mykolaiv, Ukraine

4 Research Centre of Astronomy \& Geophysics of MAS, Ulaanbaatar, Mongolia

${ }^{5}$ Institute of Solar-Terrestrial Physics, SB, RAS, Irkutsk, Russia

${ }^{6}$ Keldysh Institute for Applied Mathematics, RAS, Moscow, Russia
} 


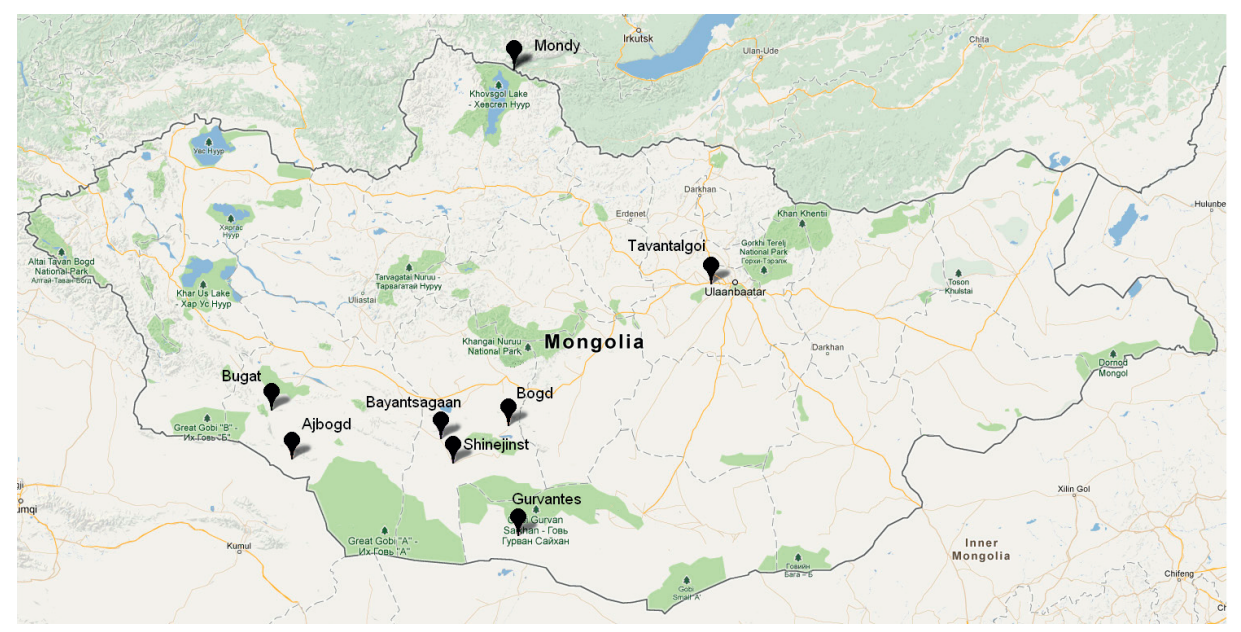

Fig. 1. Map of the sites.

Data selection. In the first stage we use only data obtained during night time in 23 p.m, 2 a.m. and 5 a.m. of local time. Cloud amount parameter lies in the range $0-10$, and was estimated by visual method. Also we used the ground wind speed and wind direction data. In the two sites, Tavantalgoi and SSO we were able to use automatic digital cloudmeters and data from digital weather stations. However in this paper we restrict our investigations only to night measurements of the three parameters.

Data reduction. We define clear sky when cloud parameter is equal to zero. If for all three night measurements (23, 2 and 5) cloud parameter equals to zero, we suggest it as a whole clear night. Then we calculate the number of clear night hours as number of measurements with cloud parameter equals zero multiplied by 3 , i.e. the time interval between successive measurements. Mean wind speed and direction is the average per three night measurements. In contrary, for Tavantalgoi and SSO sites we use data of cloudmeters taken once per 10 minutes and the number of clear hours can be calculated more correctly. Calibration of the cloudmeters are performed in comparison with images of all sky cameras taken at the same time.

Results. In Table 1 we provide results of our calculations. First column is a name of the station, next columns represent, the international index of the weather station (or observatory code), coordinates and a height above sea level. The number of clear night hours, ground wind speed and wind direction is averaged for 3 years (Jan. 2009 - Dec. 2011). For Tavantalgoi it is averaged for Nov. 2010 - Nov. 2012, and for SSO Mondy it is averaged for the period Oct. 2009 - Oct. 2012 (Fig. 2). Wind direction in degrees is presented for the Winter season.

Discussion and comparison with other sites. All of the sites have a maximum of clear nights and number of clear night hours in Fall and Winter seasons. Estimated number of clear night hours in general exceeds the same parameters for North Caucasus (e.g. Kornilov et al. 2010). In the station Ajbogd the number of clear 


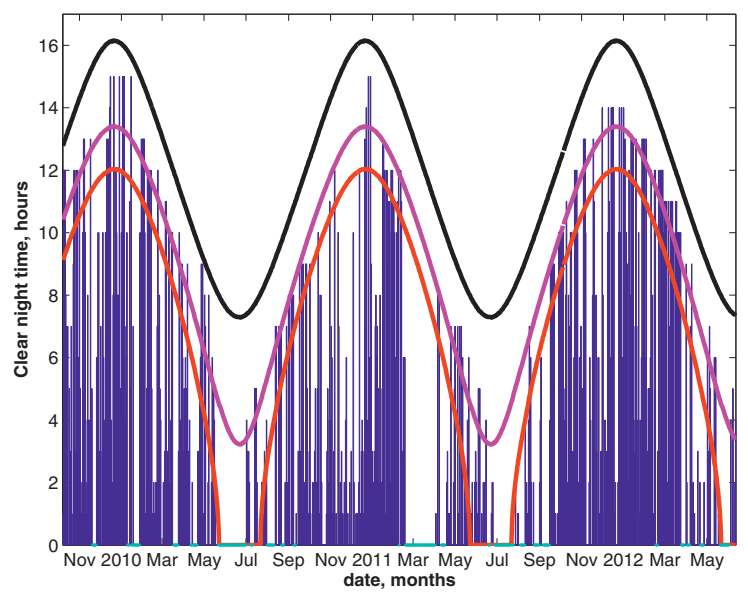

Fig. 2. Seasonal variations of number of clear sky hours in SSO (Mondy). Cyan on the $\mathrm{X}$-axis denotes data gaps.

Table 1. Weather stations and results obtained in 2009-2012.

\begin{tabular}{l|l|l|l|l|l|l|l}
\hline Station name & Index & $\begin{array}{l}\text { Latitude } \\
(\mathrm{N})\end{array}$ & $\begin{array}{l}\text { Longitude } \\
(\mathrm{E})\end{array}$ & $\begin{array}{l}\text { Height, } \\
\mathrm{m}\end{array}$ & $\begin{array}{l}\text { Clear night } \\
\text { hours }\end{array}$ & $\begin{array}{l}\text { Wind, } \\
\mathrm{m} / \mathrm{s}\end{array}$ & $\begin{array}{l}\text { Wind } \\
\text { direction }\end{array}$ \\
\hline Gurbantes & 44374 & 43.20 & 101.00 & 1726 & 1390 & 4.1 & 180 \\
Shinejinst & 44329 & 44.53 & 99.27 & 2219 & 1410 & 3.4 & 225 \\
Ajbogd & 44324 & 44.91 & 94.96 & 1442 & 1960 & 2.2 & 90 \\
Bayantsagan & 44326 & 45.05 & 98.85 & 2030 & 1410 & 2.5 & 315 \\
Bogd & 44334 & 45.17 & 100.76 & 1280 & 1580 & 4.1 & 315 \\
Bugat & 44268 & 45.55 & 94.35 & 2000 & 1330 & 3.6 & 360 \\
Tavantalgoi & $\mathrm{n} / \mathrm{a}$ & 47.88 & 106.33 & 1670 & $>1270$ & 5.1 & 315 \\
SSO Mondy & $\mathrm{C} 48$ & 51.61 & 100.92 & 2007 & $>1570$ & 3.5 & $\mathrm{n} / \mathrm{a}$ \\
\hline
\end{tabular}

night hours is close to 2000, and this region we are planning to investigate more precisely. Our direct measurements of clear night hours is somewhat less than the same parameter estimated indirectly in early publications (Batsukh et al. 1995). Detailed results of our project will be presented in forthcoming publications.

The work was supported by RFBR grant 11-01-92202-Mong_a.

\section{References}

Batsukh, D., Ganbaatar, D., Khaltar, D., et al., 1995, A\&AS, 113, 341

Kornilov, V., Shatsky, N., Voziakova, O., et al., 2010, MNRAS, 408, 1233

The atlas of the climate and ground water resources in the Mongolian's people republic, 1985, ed. D. Tuvdendorzh \& B. Myagmarzhav (Ulaanbaatar, GUGMS of Mongolia) 
